\title{
International Tourists' Behaviors and Environmental Values for Sustainability in Tourism and Hospitality Business: A Systematic Review in Hurghada Nawal Morsi Zaki ${ }^{1} \quad$ Nermeen Abuzied $^{2}$ \\ ${ }^{1}$ High Institute of tourism and hotels (EGOTH) ${ }^{2}$ Suez Canal University
}

\begin{abstract}
The tourism industry has a dramatic impact on the world's economy and development. The impacts of Travel and Tourism (T\&T) on the natural and social environment have been a long-standing focus of tourism and hospitality researches. Sustainability is a critical business issue that is becoming a mandatory requirement for sustainable tourism and hospitality business. For this reason, it is important to study international tourist' behavior, supporting sustainable production and consuming sustainable products and services that are functions of travel consumer's values. The study presented a systematic analysis that focused on sustainability values (SVs) of tourists and the provision of hotels with respect to sustainability .The empirical study used a structural data from international tourists in Hurghada - as a sustainable tourist destination in Egypt. Data were obtained how Sustainable Values (SVs) predict tourist's choice for sustainable tourism and hospitality businesses and how travel consumer' values are important in making businesses more competitive. The sample of this study consisted of 450 international tourists stayed at hotels in Hurghada -as a sustainable tourist destination- from the period of September 2016 to January 2017. The effect of the sustainability values (SVs), however, is partially mediated by the tourists' environmental behaviors. Extending the respondents' behavior, international tourists were grouped into an environment-supporting group called sustainable tourist(strong-sustainers) and an environment-normal group termed (neutral sustainers). Based on these findings to the tourism market, stakeholders could offer targeted sustainability messages for the proposed tourists (strong-sustainer).

Keywords: Tourism Sustainability; Sustainable Tourists; Sustainability Values; Sustainability Choices; Environmentally Behaviour Review; Choices Sustainable Green Hotel Facilities (CSGHF);Sustainable Destination (Hurghada) .
\end{abstract}

\section{Introduction}

Tourism is an activity in the economic sector that has grown by around $45 \%$ in the past twenty five years .It now accounts for around $23 \%$ of the world economic activity and has a major effects on the natural and built environment and on the social and cultural of the host populations (www.world scientific .com).

Tourism's future greatly depends on its capacity to meet a growing demand without increasing its environmental footprint or its pressure at the tourism destination (United Nations World Tourism Organization (UNWTO), 2015). Simply stated, tourism faces the challenge of becoming sustainable. A major issue experienced by the tourism industry in securing its future is the lack of demand for sustainable offers, services and products, both by organization in tourism and hospitality business and tourists.

The notion of sustainability has gained widespread acceptance in the tourism industry as part of a strategy to encourage the tourists to stay at green hotels. Thus, despite significant interest in improving the sustainability of services and products, there is little knowledge of the potential tourist' values as a source of motivation for booking a green room in a sustainable hotel or purchasing sustainable services from another business. 
In the new era, delivering superior travel consumer value is an essential strategy for companies in sustainable tourism and hospitality business to gain competitive advantage and long term success.

In addition, tourists make purchasing decisions based on perceived value, or the degree to which their needs and expectations about product quality, service quality, and/or price are satisfied. With an understanding of a company's mission, goals, and strategies and of its tourists' needs and expectations, the company can develop a value proposition for delivering superior value to its travel consumers. This action will allow the company to attract new travel consumers, retain existing consumer, and deliver significant profits. If a company maximizes value for its consumers, success follows.

In the tourism industry, tourist's satisfaction is one of the most important objectives in companies for sustainable tourism and hospitality business that they aim to obtain optimal longterm results. In the case of tourism, tourist's satisfaction is paramount because it is directly related to the choice of tourism destination and the decision to return (Parasuraman ,1985 Byrd, 2007).

The economic effects of the presence of international tourists in Hurghada (as a tourist destination in Egypt) stem from the fact that they spend their money on a wide variety of products and services.

This expenditure can be seen as flood of financial resources into the Egyptian economy, thereby creating new levels of travel consumer's demand. In the information society, companies in tourism business to need to be increasingly competitive especially in knowledge industries such as travel and tourism (T\&T), where information technologies (ITs) have a tremendous impact (Buhalis, 2003).

However, the effect of Sustainable Values (SVs), is partially mediated by the tourists' environmental behaviors. Sustainability studies in tourism suggest that tourists' decisions to support sustainable production and to consume sustainable services are functions of those sustainable tourists' values.

This empirical study's aim is contribute understanding of the role of sustainability values (SVs) in predicting potential sustainable tourists' choices of sustainable tourism and hospitality businesses, and the role played by sustainable tourists to a sustainable tourist destination as a strategic element.

Using a partially mediated structural equation model, It presents a systematic analysis that focuses on environmental behavior, sustainability Values (SVs) of international tourists and the provision of green hotels with respect to sustainability.

It (1) determined the (SVs) of potential sustainable tourists as travel consumers in Hurghada - as sustainable tourist destination;

(2) Examined the efficacy of Sustainability Values (SVs) scale in predicting potential travel consumers' (tourists) choices Sustainable Green Hotel Facilities (CSGHF) in Hurghada - as Sustanable tourist destinations .

\section{Theoritical Background}

Hence, it also has major impacts on the natural and built environments and on the wellbeing and culture of host populations. International tourist arrivals also have almost quadrupled and domestic tourism has intensified in most developed and newly industrialized countries. At the same time, tourists' movements have spread geographically to reach practically all countries of 
the globe, becoming for many of them an important economic sector in terms of income generation, foreign exchange earnings and employment creation.

Awareness about sustainability issues which referred originally to the natural environment and now covers the social, economic and cultural spheres as well as the built environment also developed significantly over those thirty years. The subject fields in sustainable tourism research have significantly changed over the 25-year period of analysis and, in particular, sustainable international tourist behavior is a thriving field of research.

As the World Tourism Organization (WTO) already noted over a decade ago, sustainable tourism should also maintain a high level of tourist satisfaction and ensure a meaningful experience to the tourist, raising their awareness about sustainability issues and promoting sustainable tourism practices amongst them (UNWTO,2013)

It is undeniable that tourists' (travel consumer') profile has changed significantly in recent years. In tourism study on tourist behavior indicate that there is a growing awareness of the environmental, social and cultural impact that tourism activity can generate. Tourists who promote and consume sustainable tourism are sensitive to the impacts that this activity can generate and therefore try to protect the tourism destination. However, the scientific debate regarding travel consumer behavior in sustainability issues is intense. However, many researches, suggest that most tourists (travel consumers) pay little attention to ethical considerations in their final purchase decisions; therefore, there is a gap between the expressed attitudes and actual purchase behavior (attitude-behavior or word-deed gap). From a management and research perspective, it is important to obtain a greater understanding of travel consumer behavior and economic implications of the current tourist regarding sustainability, with the aim of achieving a new tourism model whose central value is sustainability. In that sense, an important challenge facing policymakers and stakeholders is to identify which tourists are willing to pay more for sustainable tourism destinations and if pro-sustainable tourists spend more than their less-sustainable counterparts.

Values (V) play a significant role in explaining specific beliefs and behavior and can be used as predictors for other outcome variables, notably attitudes or behavioral intentions (Stern 2000; Stern and Diet 1998). An analysis of countless supplementary definitions finds that value systems generally include the following five common features 1- beliefs, 2- behaviors, 3evaluation of behavior and events, 4- transcend specific situations and 5- are ordered by relative importance (Rokeach1973; and Schwartz, 2001).

\section{Tourism Demand in Egypt}

Tourism is one of the world's fastest growing industries and is a major source of income for many countries. Tourism has taken an important role in the Egyptian economy, generating foreign exchange, creating employment, promoting development, reducing income and employment disparities among regions

The Egyptian tourism sector has lost over $\$ 19$ billion during the past five years since the revolution of January 2011. The total income of tourism to Egypt that year amounted to just over $\$ 9$ billion, with about 9.7 million tourists visiting the country.

In 2012, approximately 53 million overnight stays were registered in Egypt's hotels, a decrease of $1.29 \%$ from 2011. With the new government in place, 2012 witnessed higher levels of security and stability than 2011 as efforts to attract guests back to Egypt were implemented. The largest source market for Egypt in 2013 is Europe, with 8.2 million tourists (70\% of tourists) visiting from the continent, followed by the Middle East with 2.0 million visitors (17\%). Africa, Asia and 
North America each accounted for around 4\% of inbound tourists to Egypt in 2013 .In August 2013, European tour operators' suspended journeys to the country due to the popular uprisings and the subsequent lower security levels in Egypt.

In 2015 was the worst of the past five years, due to the negative impacts of several tragedies that began with the assassination of Attorney General Hisham Barakat mid-year and followed by the deaths of the ten Mexican tourists in September in the Western Dessert, and the Russian plane crash in October. Revenues this year will not exceed $\$ 5.5 \mathrm{bn}$, compared to $\$ 7 \mathrm{bn}$ last year .

In 2012, approximately 53 million overnight stays were registered in Egypt's hotels, a decrease of $1.29 \%$ from 2011. With the new government in place, 2012 witnessed higher levels of security and stability than 2011 as efforts to attract guests back to Egypt were implemented. BMI forecasts a drop in the number of overnight stays for the next few years, down from 51.8 million in 2010 to 51.7 million in 2017, primarily the result of the recent political and social instability. Whilst Egypt's resort hotels and all-inclusive mostly target Europeans, luxury hotels are primarily frequented by the domestic market and tourists from the Gulf Cooperation Council, with only a small portion of Europeans. Direct flights from European source markets to Hurghada benefit hotels and therefore make them attractive for investors to develop more properties, despite the discounted rates witnessed as of late. Approximately 17 new properties with 5,900 rooms are expected to be under construction in Egypt. The majority of which will be launched in the coastal area of Hurghada, which is relatively more stable and safe compared to Cairo (http://www.worldbank.org).

\section{Hurghada as a Sustainable Tourist Destination}

Being a people-oriented industry, tourism also provides many jobs which have helped revitalize local economies. However, like other forms of development, tourism can also cause its share of problems, such as social dislocation, loss of cultural heritage, economic dependence and ecological degradation. Learning about the impacts of tourism has led many people to seek more responsible holidays. These include various forms of alternative or sustainable tourism such as: nature-based tourism, ecotourism and cultural tourism. Sustainable tourism is becoming so popular that some say that what it presently call alternative will be the mainstream in a decade. All tourism activities of whatever motivation, holidays, business travel, conferences, adventure travel and ecotourism need to be sustainable.

Sustainable tourism is defined as tourism that respects both local people and the traveler, cultural heritage and the environment. It seeks to provide people with an exciting and educational holiday that is also of benefit to the people of the host country.

Tourism is a lucrative and growing business for Egypt leading its tourism sector to consider the characteristics of sustainable tourism as a means of maintaining local resources and heritage. While tourism can add a great deal to the Egyptian economy, it also has the potential to take away a number of key components of Egypt.

Sustainable tourism is a concept in which respect for the local resources, culture, environment and people of a locale is emphasized in a way that is also beneficial for tourists.

Egypt's beaches and climate are spectacular, and the Red Sea is one of the best scuba-diving sites in the world. The Red Sea coast is one of the most important tourist areas that attract huge numbers of foreign tourists each year, based in large part on its unique and fragile marine environment. Most of the tourists visit this area to enjoy the natural environment: such as diving, windsurfing, rowing and water polo. Tourism development on the coast began in the eighties as separated tourist villages without a prior integrated plan for the whole region. 
Year-round sunshine, clear waters and magnificent corals, wild deserts, natural protectorates and mountains all make Hurghada that locates in the Red Sea Governorate in Egypt - an ideal tourist destination.

The Egyptian Red Sea shore extends with 1080 kilo .Meters known for its rich fauna and flora, particularly coral reefs and numerous fish species with a big number of unique marine habitats, including sea-grass beds, salt-pans, mangroves, coral reefs and salt marshes. Hurghada 's shore offering the world's best water sports activities, tourist find superb visibility (up to 50 meters) that abundant diverse fish life (over 1,000 species) countless varieties of hard and soft coral (over 200 species), year-round diving in comfortable water temperatures (18 to 26 Celsius) incredibly diverse underwater topography and spectacular wall and shipwreck destinations, sunny weather and pleasant air temperatures (18 to 35 Celsius), and easy access to diving locations. It is no surprise therefore that the area is one of the most sought-after holidays destinations. As a tourist in Red Sea Governorate you will enjoy recreational tourism ( Diving, Snorkeling, kite surfing ) or Claim onotherapy \& wellness centers or Historical tourism or Religious tourism Hurghada (as a coastal city) has become a particular focus for preservation efforts. One of its major assets is its marine environment, which is also fragile and susceptible to damage. Some of the steps proposed to ensure the longevity and health of these assets are a land use plan, the creation of protected areas, the establishment of nature preserves, the installation of buoys to protect the coral, the introduction of environment management systems for resorts, the creation of a standard environmental impact assessment, the introduction of best practices and the development of an awareness campaign. Zoning and the improvement of relevant information, especially geographic information system mapping, are central to the strategy (www.state.gov).

\section{Sustainable Tourism and Hospitality Businesses in Egypt}

In early 2015 the Global Sustainable Tourism Council announced that Egypt's Green Star Hotel programed had received - recognized- status from the organization. Under the programed, which was developed with the assistance of Germany and is overseen by the Egyptian Ministry of Tourism, 57 hotels and resorts have passed the Green Star Hotel capacity building programed and are certified Green Star Hotels for their environmental and social standards. . With The implementation of the Green Star Hotel system in the hotels, a dynamic process towards more environmentally friendly operation and management was initiated. For example, four pilot destinations have already established garbage recycling plants for their Green Star hotels.

\section{Tourism Sustaiability and Sustanable Tourists}

Tourism's sustainability is a much debated issue. Without any pretension of being exhaustive dimensions of sustainability is often negative, and that thus current tourism development is unsustainable (UNWTO, 2013). Tourism unsustainability can affect its future both directly and indirectly. Directly, it can damage its natural or cultural basis. Consider, for example the impact that the rise of sees' levels might have on costal destinations such as the Maldives (Becken and Hay, 2012). Indirectly, it can bring its social license to operate (SLO) in danger. (SLO) refers to the acceptance by society of business activities. A (SLO) is lost when society concludes that the economic value created by a business is outweighed by its negative impact in other areas (Williams , 2007). That tourism might lose its SLO has been powerfully illustrated with the concept of (assault on pleasure) (Yeoman, 2011). Building on existing studies, Yeoman argues that by 2030 the New Puritans might forego the pleasure of tourism due to the negative impact it has on other values they cherish, such as a healthy natural environment or strong social ties. Though a ban on tourism might seem farfetched, society is definitely aware of the negative 
environmental pressure of tourism (Yeoman, 2011). Framed from a socio- psychological perspective the future of tourism implies a dilemma between self-enhancing values (a pleasurable experience) and self-transcending ones (protection of the environment and communities from the disruptive effects of tourism). Sustainable tourism, though, might offer a path to reconcile both sets of values. It is a form of tourism that creates value on an economic, environmental and social dimension (UNWTO, 2013; Timmermans and Cavagnaro, 2013). The three-dimensionality of sustainability is a point that should be insisted on, as a form of tourism that respects the environment and promotes the well-being of local communities but is not economically feasible will not be sustainable in the long run (Yeoman, 2012).

Tourism should become more sustainable, a process that need the participation of all policymakers of authorities and stakeholders. In fact, the main role of the sustainable tourist - a tourist with sustainable or pro-sustainable attitudes and behaviors- the main actor of the tourism system, is crucial in advancing towards sustainable tourism. It should be stressed that tourists' sustainability must be understood as a pro-process rather than a static state; it must be considered a permanent process of adaptation and balance to adjust their relationship with ecological, economic and social systems.

Summarizing: the future of tourism might be at stake if self-enhancement values and selftranscendent values are not reconciled in the choice for a more sustainable tourism experience. This explains the interest in exploring how values influence sustainable tourism behaviour.

Values Influencing Sustainable Choices And Tourist's Behaviors

Values (V) are cognitive representations of abstract goals (e.g., a world at peace) or abstract means of behaving (e.g., being helpful) that vary in importance. Similar to needs, desires, and goals, they function as motivational constructs that guide a person's behavior, but unlike specific goals and desires, they transcend situations (Schwartz, 2000) for an analysis of the value construct.

Values (V) can be clustered according to the type of motive they serve. Such a cluster is referred to as a value type. For instance, being helpful and loyal serves the motive of the value type benevolence. Compatible value types

(E.g. Benevolence and universalism) can further be clustered into a value orientation (e.g., selftranscendence).Schwartz examined the Inter-relationships among 56 values across cultures using multi-dimensional scaling. The results showed that these values could be reduced to ten value types located along two orthogonal value orientation dimensions. As shown in Figure (1), the first dimension ranges from a self-enhancement to a self-transcendence value orientation, whereas the second dimension ranges from conservatism to openness-to-change. Of particular importance for the present thesis are the self-transcendence and self - enhancement value orientations, since previous studies have linked these value orientations to pro-environmental attitudes and behaviors (e.g., Nordlund , 2002 and Woodall, 2003).

Self-transcendence. Self-transcendence is a social-altruistic value orientation, closely related to what in another line of research is conceptualize as a pro-social value orientation (Van Lange et al., 1997). The former value orientation comprises two value types, universalism and benevolence. The motivational goal of universalism is improving the welfare of all people.

Schwartz's value theory identifies the following ten broad values according to the motivation that underlies each of them: achievement, benevolence, conformity, hedonism, power, security, self direction, stimulation, tradition and universalism- we apply these values as part of our hypothesis development. The total number of values that people consider in connection with a decision is 
relatively small, so the study of values is an economically efficient approach for describing and explaining similarities and differences in people's actions (Rokoach 1973).

So, regarding to Schwartz proposed a cultural-values theory out of the need to account for individual differences in value priorities and their effects on attitudes and behavior across cultures (Schwartz .2006).

As general, values are cognitive demonstrations of the important human goals or motivations with which people must transfer to coordinate their behavior (Bilsky and Schwartz 1999) and also underline value orientations (patterns of basic beliefs), which influence attitudes and behavioral intentions and behaviors (Vaske and Donnelly 1992).

In Tourism research study, researchers of the relationship between values and tourist's behavior in the tourism and hospitality business have been scare.

Pizam and Calantone provided the seminal work relating tourist behavior to personal values (V). Some studies using varying value scales, as value survey (Rokeach 1973), List of values (Kahle 1983) values and lifestyles (Mitchell 1983).

Dunlap (2008), looked at value orientations on the cultural level by segmenting the Norwegian population according to personal values.

Dalen, Suggested that segmentation could be applied to the field of tourism and could account for different types of tourist behavior.

Another study that empirically applied the typology to Norwegian tourists concluded personal values provide powerful explanations of tourism behavior (Mehmetoglu et al. 2010).

Values (V) in sustainable tourism development have been articulated by various governmental agencies, nongovernmental organizations, and environmental groups, one research provided a stepping stone for future research in this area by creating a scale with which to measure sustainability value (Shepherd, Kuskova, and Palzelt 2009). Also there is need for multiple scales to measure the values that underline sustainable tourism development, where the values are: freedom, equality, solidarity, tolerance, respect for nature, and shared responsibility, thus, we offer the following hypothesis to be examined.

- Hypothesis 1: The Sustainable Values (SVs) predict choices of potential sustainable tourists for sustainable tourism and hospitality businesses in Hurghada -as sustainable tourist destination .

\section{Eniveromental Values and Tourists' Behaviors}

Some studies have shown a link between individuals' values and their expressed environmental concern and behaviors (De Groot 2006 and Stern et al. 1995).

Some researchers suggested that values of self-transcendence values (combination of universalism and benevolence) were positively correlated with self-reported environmental behavior (EB) while self-enhancement values (combination of power and achievement) were negatively correlated with environmental attitudes and self reported behavior (Schultz 1999 and Stern et al. 1999). While the direct relationship between values and (EVB) is weak. Research has concluded that values play a role in specific situations when they are activated by a set of altruistic situations when they are activated by a set of altruistic concerns, and these value types a positive relationship with proenvironmental attitudes and behavior (ie Hansla 2008 andSchwartz 2009).

On the travel consumer side, the theory of planned behavior (Ajzen, 1980) and its theoretical extensions have been applied extensively to examine factors influencing Travel consumers' green hotel choices (Heesup Han, 2010). While existing research have assiduously modeled and empirically tested how consumer environmental values and belief influence travel consumer 
attitudes and behavioral intention towards hotel choices (Chien-WenTsai, 2008). A second important consideration is social support and social structure. When people carry out specific environmental behavior, structural variables should be understood.

The characteristics of social setting can act as facilitators and inhibitory factors of responsible environmental behavior.

According to Han (2010), the interaction between personal and social structural variables can be defined in terms of the degree of conflict or consistency between the two. This conflict will be high when personal and structural variables are of different signs, that is, when there is positive personal disposition to action but the structural makes it difficult, or when personal disposition to act is negative and the structural facilitates it. Customers' evaluation of the level of inhibitionfacilitation presented by the social structure will affect personal environmental attitude and behavioral intention.

According to Irene (2002), attitude toward the behavior refers to the degree of a person's positive or negative evaluation/appraisal of behavior performance.

Chien (2008), found that the primary predictor variable for green consumption behavior is green consumption behavioral intentions, which are primarily affected by attitude. This attitude is based on salient behavioral beliefs and values. Thus, this perception of value is inextricably linked to a travel consumer's attitudes concerning any issues surrounding that purchase, and will directly influence their purchase decision (Woodall, 2003).

Household recycling requires that at least one household member collect, sort, store, and in some cases, transport waste materials to recycling centers (e.g. Bruvoll, Halvorsen 2002,Berglund 2009; Sidique, Lupi and Joshi 2010). Why individuals adopt and persist in these behaviors is an important question not only for the development and conduct of recycling programs but also an issue to which social scientists have devoted considerable attention (Berger 1997; Breichen 1999; De Young 1985; Dunlap and York 2008; MarquartPyatt 2007).

Directly related to matters addressed in this study is the work concerning the influence of social context in the shaping of environmental attitudes and behaviors. Derksen and Gartrell (1993) observed that not only did the social context have a strong and independent effect on recycling behavior (Woodall, 2003 but that the link between attitudes and behavior was dependent on establishing a connection between the individual and a particular social context (Derksen 1993). Olli (2001) found that the contextual factor of participation in environmental organizations was a stronger explanation of pro-environmental behaviors, like recycling, than any other correlates of environmental behavior, including demographic characteristics and attitudes concerning environmental issues.

A study of recycling in European societies noted that conservation behavior is greatly influenced by the context of ecological mobilization in which it occurs (Guerin, Crete and Merecier 2001). Blake observed that environmental attitudes and behaviors in British Columbia may be context dependent. What people are concerned about can be affected by their actual experience of environmental conditions. Additionally, environmental action can encompass different kinds of behaviors, which themselves may be shaped by context.

Sarigollu found that differences in environmental attitudes and behaviors between Turkey and Canada had a basis in the cultures of those two societies. Variations in the environmental motives and behaviors between European and Asian New Zealanders were related to particular ethno-cultural characteristics of these populations (Milfont, Duckitt and Cameron 2006). Situational factors such as curbside collection of waste, availability of space for storage of recyclable materials and the presence of accessible recycling centers have all been identified as 
influencing recycling rates (Corral-Verdugo 2003; DeYoung 1985-86; Statistics Canada 2010; Vining and Ebreo 1990).

Some researchers found that support of recycling could be predicted by Schwartz's altruism model (Nielson and Ellington (1983), Hopper and Nielsen (1991), and vining and Ebreo (1992). However, Guagnano (1995) did not find that Schwartz's model was always predictive of (EVB) intentions.

They contend that Schwartz's model interacts with external conditions, and that the attitude behavior relationship is a curvilinear function resulting from the interaction of personal variables and external condition Stern and Dietz and Stern broadened the model to include environmental attitudes and behavior. They content that three different value orientations may affect beliefs related to (EVB) : an egoistic orientation (the person himself or herself), a social altruistic orientation (people in general and a biosphere value orientation- another several research have found that pro-environmental beliefs, intentions, and behavior appear to be positively related to altruistic or biosphere values and negatively to egoistic value (Stern, 1998; van, and Van Lange 1995).

Most studies of individual environmental values use surveys not direct observations of environmentally consequential behavior.

Values (V) are most commonly related to either:

1- Self-reported behaviors as do you usually recycle newspapers

2- Behavioral intentions as would you be willing to sign a petition in favor a stricter environmental protection

3- Other measures that express concern for the environment. Few studies examine actual behavior.

It is well established that the link between self-reported behavior or behavioral intentions and actual behavior is far from perfect. Other limitation is that the relationship between values and behavior can be dependent on the type of values being examined. The important area of the study examines the relationship of values to stated willingness to pay or otherwise make sacrifices to protect the environment.

Little research has been done in this area to address this gap, we offered the following hypotheses. Few studies examine actual behavior. It is well established that the link between self-reported behavior or behavioral intentions and actual behavior is far from perfect. Other limitation is that the relationship between values and behavior can be dependent on the type of values being examined. The important area of the examination is the relationship of values to stated willingness to pay or otherwise make sacrifices to protect the environment. In this area the study concern to address this gap, we offered the following hypotheses:

- Hypothesis 2: Environmental' Behavior (EnBs) affect sustainable tourists' choices of a sustainable tourism and hospitality business a sustainable tourist destination.

- Hypothesis 3: Sustainability Values (SVs) predict sustainable tourists' choices of sustainable tourism and hospitality business indirectly in Hurghada -as sustainable tourist destination - via Environmental Behavior (ENB) .

Hence, the choice of a sustainable tourism and hospitality business is partially mediated by Environmental' Behavior (EnB) of sustainable tourists.

\section{Methodology}

- The Data Source 
The data for the present study were collected by means of a questionnaire survey distributed to over 450 international tourists stayed at stare rated hotels in Hurghada - as a tourist destination in Egypt - during the peak time, from September 2016 to January 2017. 365 international tourists responded, yielding a response rate of $81.11 \%$ that $19 \%$ of the returned questionnaires were excluded from the analysis because of incomplete.

\section{Sample Formation}

The purpose of this study is to analyze the efficacy of the sustainability values (SVs) scale in predicting potential tourists' choices for sustainable hotel facilities using a partially mediated structural equation model. Where understand the role of Sustainability Values (SVs) in predicting potential tourists' choices for sustainable tourism businesses. Therefore, the original survey dataset was restructured and formatted to suit this task.

\section{Sample Description}

It was obtained from international tourists who stays at hotels in Hurghada - as a tourist destination in Egypt- that Sustainability Values (SVs) prediction potential sustainable tourists' choices for sustainable tourism businesses. In addition to Hurghada, green hotels that surprisingly the survey provides unique insight into the Sustainability Values (SVs) and prediction of sustainable tourists ' choices. The survey questionnaires included two main sections:

- The first section

The first section was investigated the demographic data of respondents for age, gender, ethnicity, income, region, and education.

- The second section

The second section was contained the factors related to preference for a sustainable tourism business, universal sustainability values, and environmental behavior of the potential sustainable tourist(travel consumers )were obtained, the participants were asked to indicate their opinion about the statements based on a Five Point: Liker Scale ranging from one (1) totally strongly disagree to Five(5) totally strongly agree.

The Choice of the tourists of a sustainable green hotel facility (CSGHF) was conceptualized as a one-dimensional consisting of five items:

1- The Choice of the international tourists of Hurghada as a tourist destination in Egypt .

2- The Choice of the international tourists of tourism and hospitality facilities that participate in environment partner ships or certification programs.

3- The Choice of the international tourists of a green hotel that actively recycle materials.

4- The international tourist's image for environment-friendly service provider signs before making reservations.

5- The Choice of the international tourists of a green hotel that actively improve Egypt's image.

6- The international tourist's existence in tourist destination that provide environment friendly service /facilities (i.e., low toxicity, organic foods, locally products) .

Environmental behavior (EnB) of the potential tourists was identified using two general domains.

- First domain

Environmentally Active Behavior (EnAB).

Which consisting of four items:

A- I talk with friends about Hurghada as a sustainable destination 
B- I talk with friends about the environmental issues.

C- I have pointed out un-ecological behavior to someone else.

D- I buy products or service in refillable packages.

E- I read about the environmental issues.

F- I encourage friend and family to visit Egypt.

- Second domain

- Recycling behavior

- Which consisting of two items:

- I encourage friends and family to recycle.

- I look for ways to reuse things.

- Finally, the Sustainable Tourism Development Values (VSs), consisting of six factors, each factor contain numbers of items.

- Sustainable Tourism Development Values

1- Freedom

Individuals deserve lower levels of justice.

2- Equality

The nations that faster economic development the most deserve greater access to its benefits. Individuals who contributed the most to economic development deserve greater access to its benefits. The country that is responsible for economic prosperity should receive more of the resulting benefits.

3- Solidarity

Peace within societies in variability begins with promoting the society's traditional way of life. There are some people's beliefs that do not deserve respect. In some cases, it becomes necessary to repress differences across societies.

4- Respect for nature

Individuals need only make minor change to their current consumption out of respect for nature. Current patterns of production only require minor adjustments to protect the welfare of the natural environment. Sometimes some natural resources need to be sacrificed for important developments. To a certain extent, the natural environment will look after itself to the benefit of future generations.

5- Shared responsibility

Individuals are responsible when members of their immediate society do not tolerate cultural differences but are not responsible for the behavior of members of distant societies.

A civilized nation must accept responsibility for improving the welfare of its less fortunate citizens but is not responsible for the welfare of another nation's citizens. They are responsible for assuring that individual within our society have their rights for freedom maintained but we are not responsible for these rights for people in other societies. Each civilized nation should focus on ending injustices in their own borders and not influence other nations in their efforts participants.

\section{Empirical Analysis}

This study utilizes a Structure Equation Model (SEM) to analyze the influence of sustainability values (SVs) in predicting potential sustainable tourists' choices for sustainable tourism and hospitality businesses. Each individual in the Model (SE) has the option of choosing from among the alternatives. 
After data were collected it was revised, coded and fed to statistical software (SPSS) version 20. The given graphs were constructed using Microsoft excel software.

All statistical analysis was done using two tailed tests and alpha error of 0.05. (P value) less than or equal to (0.05) was considered to be statistically significant.

Regarding scoring system, the items discrete scores for each scale (sustainable service, environmental behavior or values) were summed together then the sum of scores for each dimension and total score was calculated by summing the scores given for its responses.

Descriptive statistics included the composite mean with standard deviation for the numeric data while percent to describe the frequency of each category for categorical data.

Correlation analysis between different measured parameters was done using Pearson correlation coefficient to study the bidirectional relation between domains.

Structural equation model was used to identify the (direct and indirect) relation between sustainable service and environmental behavior and the sustainable tourists' effect on sustainable values (SVs).

The research:

1- Determines the Sustainable Values ( SVs) of potential sustainable tourists .

2- Assesses the extent to which Sustainable Values (SVs) scale predicts choices for Sustainable Green Hotel Facilities (CSGHF).

Table 1. The sample distribution according to the characteristics of the selected sample of sustainable tourists

\begin{tabular}{|c|c|c|c|}
\hline \multicolumn{2}{|c|}{ Demographic data } & No & $\%$ \\
\hline \multirow{2}{*}{ Gender } & Male & 141 & $70.5 \%$ \\
\hline & Female & 59 & $29.5 \%$ \\
\hline \multirow{6}{*}{ Age } & $18-$ & 41 & $20.5 \%$ \\
\hline & $25-$ & 81 & $40.5 \%$ \\
\hline & $35-$ & 35 & $17.5 \%$ \\
\hline & $45-$ & 20 & $10.0 \%$ \\
\hline & $55-$ & 14 & $7.0 \%$ \\
\hline & $65+$ & 9 & $4.5 \%$ \\
\hline \multirow{5}{*}{ Ethnic composition } & White & 122 & $61.0 \%$ \\
\hline & African American & 29 & $14.5 \%$ \\
\hline & Hispanic & 31 & $15.5 \%$ \\
\hline & Arabic & 13 & $6.5 \%$ \\
\hline & some other ethnic back ground & 5 & $2.5 \%$ \\
\hline \multirow{3}{*}{ Education } & HIGH school & 131 & $65.5 \%$ \\
\hline & Graduate & 40 & $20.0 \%$ \\
\hline & Post-graduate & 29 & $14.5 \%$ \\
\hline \multirow{4}{*}{ Monthly income (LE) } & $<5000$ & 28 & $14.0 \%$ \\
\hline & $5000-$ & 96 & $48.0 \%$ \\
\hline & $10000-$ & 58 & $29.0 \%$ \\
\hline & $15000+$ & 18 & $9.0 \%$ \\
\hline
\end{tabular}

Font (2000) confirmed in his study that age, educational level, nationality and occupation are the determinant variables in the travel decision process. 
In the present study, tourists' demographic patterns such as age, gender, socio-economic background) and tourists' behavioral patterns were examined during the satisfaction behaviour based evaluation process.

Table (1) shows the sample distribution according to the characteristics of the selected sample of international tourists. It indicates that the sample majority $70.5 \%$ was male and $29.5 \%$ were female.

The highest percentage of international tourists between the ages of 25-35 years was $40.5 \%$ were participating in this study while the lowest age of international tourist's $\leq 65$ years was $4.5 \%$.

The highest percentage of Ethnic composition was $61.0 \%$ for white while the lowest percentage was $2.5 \%$ for some other ethnic back ground.

The education of the sample was $65.5 \%$ high school, followed by $20 \%$ graduate and the lowest percentage was $14.5 \%$ for post-graduate.

The majority of respondent had monthly income $5000 \$(48 \%)$ followed by $10,000 \$(29 \%)$ while the lowest monthly income $15,000 \$(9 \%)$.

Table 2. Descriptive of constructs and square root of average variance extracted

\begin{tabular}{|c|c|c|c|c|}
\hline Domain & $\begin{array}{c}\text { Composite } \\
\text { Mean }\end{array}$ & SD & Mode & $\begin{array}{c}\text { Reliability ( } \alpha- \\
\text { Cronbach's) }\end{array}$ \\
\hline & 2.27 & .61 & Neutral & 0.97 \\
\hline $\begin{array}{l}\text { Choice of Sustainable Green Hotel } \\
\text { Facility (CSGHF) }\end{array}$ & 2.04 & .50 & Neutral & 0.86 \\
\hline $\begin{array}{l}\text { Environmental behavior of the } \\
\text { potential tourists (EnB) }\end{array}$ & 2.00 & .43 & Neutral & 0.88 \\
\hline Environmentally active behavior & 2.0 & 0.52 & Agree & 0.71 \\
\hline Recycling behavior & 2.0 & 0.7 & Agree & 0.86 \\
\hline Sustainable Development Values & 2.05 & 0.57 & Agree & 0.78 \\
\hline Freedom & 2.04 & .65 & Agree & 0.71 \\
\hline Equality & 1.94 & .63 & Disagree & 0.69 \\
\hline Solidarity & 2.06 & .56 & Neutral & 0.70 \\
\hline Tolerance & 2.18 & .60 & Agree & 0.86 \\
\hline Respect & 2.24 & .50 & Agree & 0.81 \\
\hline $\begin{array}{l}\text { Shared Responsibility Choice of } \\
\text { Hurghada as a tourist destination }\end{array}$ & 2.16 & .55 & Agree & 0.89 \\
\hline
\end{tabular}

Table (2) showed that correlation matrix of constructs and square root of Average Variance Extracted (AVE), where indicated that the tool validity and reliability measures, where the tool was reliable at all its domains and Cranach's exceeding.

The model's three domains,(CD) (CSGHF), (ENB), and (SVs), have high reliability coefficient and display excellent convergent and discriminant properties (Reliability, $\alpha$-Cronbach $0.86,0.88$ and 0.78 ) respectively .

Table 3. Overall domains distribution among International tourists in Herghada

\begin{tabular}{|c|c|c|c|c|}
\hline \multirow{2}{*}{ Domain } & \multicolumn{2}{|c|}{ CSHF } & \multicolumn{2}{c|}{ EvB } \\
\cline { 2 - 5 } & $\mathrm{r}$ & $\mathrm{P}$ & $\mathrm{r}$ & $\mathrm{P}$ \\
\hline Choice (CSNHF) & 1 & & .616 & $.001^{*}$ \\
\hline (EnB) & .616 & $.001^{*}$ & 1 & $.002^{*}$ \\
\hline Freedom & .157 & $.026^{*}$ & .210 & $.003^{*}$ \\
\hline
\end{tabular}


International Journal of Heritage, Tourism and Hospitality Vol. (11), No. (3/2)

Special issue on papers of the $10^{\text {th }}$ ICTH (2017) organized by Faculty of Tourism and Hotels, Fayoum University

\begin{tabular}{|c|c|c|c|c|}
\hline Equality & .408 & $.001^{*}$ & .543 & $.001^{*}$ \\
\hline Solidarity & .203 & $.004^{*}$ & .239 & $.001^{*}$ \\
\hline Tolerance & .310 & $.001^{*}$ & .588 & $.001^{*}$ \\
\hline Respect & .594 & $.001^{*}$ & .532 & $.001^{*}$ \\
\hline Shared Responsibility & .420 & $.001^{*}$ & .687 & $.001^{*}$ \\
\hline
\end{tabular}

r: Pearson correlation coefficient

$* \mathrm{P}<0.05$ (significant)

Table (3) showed that overall domains distribution among international tourists in Herghada, there is significant positive correlation between two values domains (EnB) and (CSGHF) where $(\mathrm{EnB})$ showed significant positive correlation with $(\mathrm{CSGHF})(\mathrm{r}=0.616 ; \mathrm{P}<0.05)$ and freedom showed significant positive correlation with $(\mathrm{CSNHF})$ and $(\mathrm{EnB})(\mathrm{r}=0.157 ; \mathrm{p}<0.05$ and $\mathrm{r}=$ $0.210 ; \mathrm{p}<0.05)$ respectively. Also all of the rest of sustainability development values (SDV) (Equality, solidarity, tolerance, respect and shared responsibility) showed significant positive correlation with (CSGHF) and (EnB).

Table 4. Regression Weights: (Group number 1 - Default model)

\begin{tabular}{|c|c|c|c|c|c|c|}
\hline & & & Estimate & S.E. & C.R. & P \\
\hline Environmental Behavior & $<---$ & SV & 1.338 & .120 & 11.106 & $* * *$ \\
\hline Shared Responsibility Comp & $<---$ & SV & 1.000 & & & \\
\hline Respect & $<---$ & SV & .741 & .082 & 9.093 & $* * *$ \\
\hline Tolerance & $<---$ & SV & 1.001 & .096 & 10.394 & $* * *$ \\
\hline Solidarity & $<---$ & SV & .221 & .098 & 2.253 & .024 \\
\hline Equality & $<---$ & SV & .867 & .104 & 8.313 & $* * *$ \\
\hline Freedom & $<---$ & SV & .245 & .114 & 2.161 & .031 \\
\hline Recycling Behaviour & $<---$ & $\begin{array}{c}\text { Environmental } \\
\text { Behavior }\end{array}$ & 1.000 & & & \\
\hline Active Behaviour & $<---$ & $\begin{array}{c}\text { Environmental } \\
\text { Behavior }\end{array}$ & .531 & .086 & 6.199 & $* * *$ \\
\hline (CSGHF) & $<---$ & (SV) & 4.038 & .442 & 9.129 & $* * *$ \\
\hline (CSGHF) & $<---$ & EnvironmentalBehavior & -.251 & .231 & -1.088 & .276 \\
\hline
\end{tabular}

Table (4) showed that standardized path coefficients (Regression Weights): (Group number 1default model). Where Regression had positive relation between all measured indicators and all confection had significantly also show the standardized total-direct and indirect- effect of (SVs) on (CSGHF) is 0.675. That is, due to (direct and indirect) effects of Sustainable Development Values (SVs) on Choice of Sustainable Green Hotel Facilities (CSGHF).

The results of analysis supported the reliability and validity of the three scales comprising this tool. A confirmatory factor analysis using the maximum likelihood estimator of (AMOS 20) and the covariance matrix as the input was used to test the measure's convergent and discriminant validity the models three domains- Sustainable Development Values (SVs) on Choice of Sustainable Green Hotel Facilities (CSGHF), Environmental Behavior of the potential sustainable tourists (EnB), and Sustainable Development Values (SVs)-that have high reliability coefficients and display excellent convergent and discriminant properties, Average Variance Extracted (AVE). 
Figure1. Structure Equation Model

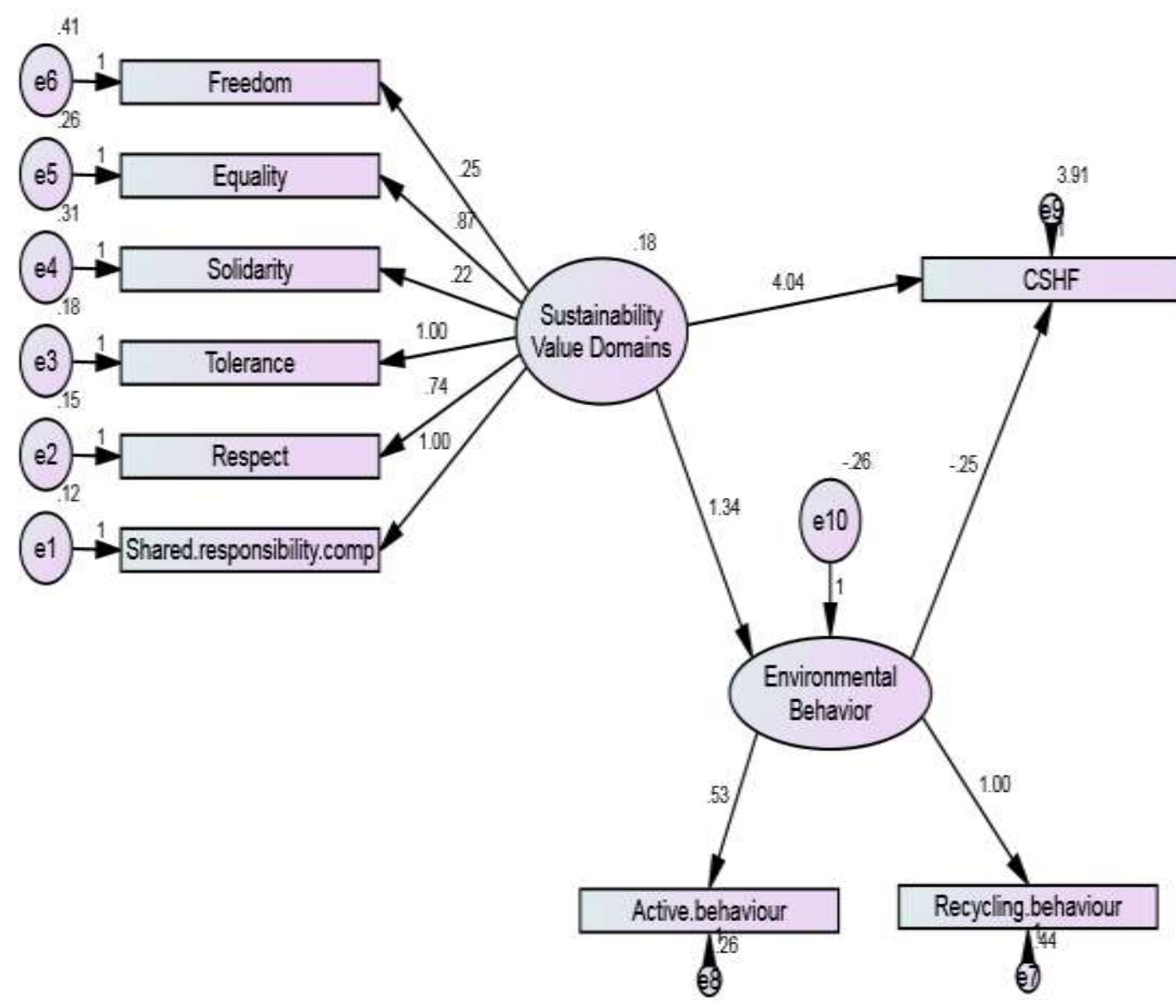

This model study (directly and indirectly) interrelationship between: Choice of Sustainable Green Hotel Facilities (CSGHF); Environmental Behavior of the potential sustainable tourists (EnB) in Hurghada (as a tourist destination ) ; Sustainable Development Values (SVs) - as sustainability values directly affected (CSGHF) and indirectly affected through (EnB).

\section{Discussion}

To date, a wealth of the present study has been conducted to examine the efficacy of Sustainability Values (SVs) predicting potential travel consumers' (tourists') choices - in Hurghada as a tourist destination in Egypt - for Sustainable Green Hotel Facilities (CSGHF).

This study builds upon the previous research studies in the literature, and addresses some specific limitations of earlier studies in the field of tourism and sustainable tourists. In particular, the study jointly represents an examination of sustainable tourist (travel consumer) attitudes and behavioral intention towards environmentally responsible practices of green hotels in Hurghada as a tourist destination in Egypt.

Several research studies found that tourists who already participated in general proenvironmental behavior practices of travel consumer (sustainable tourists ) of the tourist destination, were more likely to choose to stay at a green hotel, over those who did not (Baker, M.A.; Davis, E.A.; Weaver, P.A. 2014 ; Noor, N.A.M.; Kumar,2014) . 
A tourists' behavior is therefore a key mediator of their intention to travel to sustainable tourist destination and stay at a green hotel.

Green hotel rooms are more expensive than non-green hotels, higher income bracket tourists are more likely to stay at green hotels, while consumers have reported being willing to pay a $3 \%$ up to $6 \%$ premium for green hotels, although the long-term maintenance of such premiums is unknown given the widespread adoption of at least some sustainability measures, e.g., reuse of towels, by accommodation properties (Nepal, S.K.2007; Chan, J.K.L.; Baum, 1998).

Meanwhile, sustainable tourists (travel consumer) stay in green hotels is likely to pay more than those in normal hotels.

The present study exhibited that respondents (sustainable tourists) in green hotels in Hurghadaas a sustainable tourist destination- demonstrate a high level of willingness to pay more for the hotels involving green practices.

Those sustainable tourists with a higher knowledge of green hotels and their practices were more likely to stay in them, although experiences of sustainable practices may have a positive effect on environmental behaviors. So this present study validates a positive relationship between international tourists ' attitude tourists - as sustainable travel consumer - and their behavior towards green practice green hotels (Choi, G. \& Parsa, and H.G.2008).

In another cross-culture research, Choi, G. \& Parsa, H.G. (2009) reviewed travel consumer attitudes towards green practices and willingness to pay.

Furthermore, the results of the study reveal that sustainable tourist in green hotels which have higher environmental concerns than those in the normal hotels. Confirming that differences in cultural and social structure determines a travel consumer's green orientation.

The most common sustainable hotel practices that sustainable tourists appeared to value and think of were the use of recycle bins and recycled products, as well as reusable towel and linen schemes. Inconvenience remains a powerful barrier to travel consumers in adopting sustainable practices in hotels.

Nevertheless, the study observed a gap between international tourists intentions to travel to sustainable destination and stay in stay at green hotel and their actions to do so.

Company size appears to have a significant impact on the sustainable practices of tourism and hospitality Business operations. Larger green hotels implement more effective and longer-term green initiatives that this was mainly due to a high level of capital, and a strong business culture, and with some evidence of the importance of being part of an international chain for which sustainability is being incorporated in brand values. Although other studies found that foreignowned and multinational subsidiary companies in Hurghada were not significantly correlated with higher participation in sustainable certification schemes and superior environmental performance. Regulatory and cultural context is therefore clearly significant.

Touching on renewable energy, Dalton, Lockington and Baldock (2008) assessed tourists' attitudes towards micro-generation Renewable Energy Supply (RES).

The study shows that international tourists in Hurhhada are more inclined to engage in green practices in restaurants; further, the green attitude significantly influences the willingness to pay a premium of up to $15 \%$ or higher over the standard menu.

Furthermore, Mair and Berginseers (2010) investigated the effect of four different kinds of inroom messages in relation to towel reuse behavior. Concerning the in-room messages, information plus request generates the stronger influence on towel reuse behavior whereas information with incentive (a donation) has the lowest impact on towel reuse. Finally, in their examination of the relationship between customer response to Eco labels and their environmental 
values, Fair-weather, Maslin and Simmons (2005) note that $63 \%$ of respondents express a bio centric attitude towards the environment while $37 \%$ exhibit an ambivalent attitude the bio centric tourists illustrate more recalling exposure to tourism Eco labels than ambivalent tourists, in addition to the willingness to choose an echo labelled accommodation.

The decision - making study discovered that values/ services reliability, resultant reputation and food quality in restaurants highly affect the selection of a green hotel among the young generation. The evaluating consumer attitudes towards green products, divulges a tremendous market potential for services in green hotels .

Price $(\mathrm{P})$, product and services quality and social responsibility are reported to have a significant impact on tourists' decision-making behavior. It is likely that individuals may reveal a different environmental attitude moderated by the activity pursued. (Andereck 2009), conducted in a visitor Centre, outlines that tourist ' perceived importance of incorporating environmental practices.

Some writers have suggested that norms play a role in guiding recycling behavior (Jackson et al. 1992; Vining and Ebreo 1992). Derksen, L. \& Gartrell, J. (1993). Dirksen and Gartrell (1993) compared the attitudes and recycling behaviors of individuals in two separate communities, one with a visible, highly publicized curbside recycling program and the other with minimal recycling opportunities. They found that persons with positive attitudes towards environmental concern will recycle if given the opportunity, but more importantly, their results also show that unconcerned individuals in the strong recycling community reported high levels of recycling. They conclude that the social context alone was sufficient to produce the behavior. They suggest that the highly visible, widespread, and socially desirable nature of the program meant that on a neighborhood basis, the norm for recycling was probably changed. As product disposition behaviors become more visible with the increased number of curbside recycling programs, one would expect the normative component of the recycling decision to become more important.

The attitudinal component of the (MSE) model of reasoned action is the multiplicative result of beliefs towards the behavior and the perceived effectiveness of engaging in the behavior. Support for the relationship between attitudes toward behavioral intentions has been mixed (Bagozzi and Dabholkar 1994; Balderjahn 1988; Kinnear, Thomas, and Taylor 1974; McCarty and Shrum 1993; Samdahl and Robertson 1989). The tenuous link between attitudes and intentions has led some researchers to examine the influence of other factors that may moderate the relationship. Berger and Corbin (1992) found that the level to which an individual perceived his or her behavior to be effective in achieving the desired results moderated the relationship between attitudes and a variety of environmentally conscious consumer behaviors. Individual differences are also hypothesized to moderate the attitude-behavioral intention relationship in the reasoned action model. Fishbein and Azjen (1975) acknowledge that the relative importance of the normative and attitudinal components in the reasoned action model depends on individual characteristics.

\section{Conclusions and Recommendations}

One of the conclusions of this study was that respondents (sustainable tourists) with more favorable beliefs about environmentally friendly initiatives used by normal hotels were more likely to sustainable value green hotels than others with less favorable beliefs about the environmentally friendly initiatives used by hotels. Other findings confirmed that respondents (sustainable tourists) with more favorable beliefs about the sustainable value provided by green hotels were more likely to participate in green activities during their stay than tourist with less 
favorable beliefs about the value provided by green hotels. Respondents (Sustainable Tourists) with more favorable beliefs about the sustainable value provided by green hotels were more willing to stay at a green hotel than respondents with less favorable beliefs about the sustainable value provided by green hotels. The last findings show that respondents (sustainable tourists)s with more favorable beliefs about the sustainable value provided by green hotels were more likely to pay more to stay at a green hotel than tourists with less favorable beliefs about the value provided by green hotels.

The study also provided some evidence that certain international tourists look for green certification hotel operations need to have green certification to target hard-core sustainers. Hotel operations need to have green certification to target hard-core sustainers. In conclusion, the data indicated that almost half of the tourism market does value sustainability. One of the implications of this finding is that leadership in this area would open up new opportunities and markets for the tourism industry. Future research can examine whether the model would behave differently for organization in tourism market, as the study focused on tourism and hospitality businesses.

Today in Egypt, the Egyptian government, tourism authorities, organizations acknowledge that, without sustainability, there cannot be development in tourism that generates benefits to all stakeholders, resources and overcomes our crises. The tourism and hospitality sectors could not remain indifferent to the sustainability challenge of our times.

In pursuit of sustainable tourism, both tourism industry and local authorities share the challenge of providing incentives for international tourists to adopt a sustainable behaviour.

As we can see, maintaining sustainability within the tourism industry in Egypt covers a number of aspects. Great care and mindfulness must be taken in order to ensure a place doesn't lose what made it appealing in the first place and that a community isn't left in ruins due to the impact of serving outsiders. These five characteristics of sustainable tourism are essential to ensuring growth of a region, its industry and its sustainable tourists.

In Hurghada as a tourist destination in Egypt, local authorities need to create the institutional contexts in which sustainable tourism products or services can be developed by the tourism and hospitality industry. At the same time, stakeholders in the tourism and hospitality business has a double challenge of, on one hand, investing in innovative sustainable products and services without the certainty of tourism market support, and, on the other hand, creating incentives for a sustainable tourist behaviour.

\section{Benefits of Sustainable Tourism and Sustanable Tourists}

Benefits Local Economic Development: There are a number of diverse opportunities for the creation of jobs locally. It also encourages local entrepreneurship in sustainable tourism and hospitality business and community reinvestment in order to sustain the economic momentum and maintain it within the local geographic region (Middle East). Outsourcing to other parts of the world is discouraged.

Benefits both Community and Environment: If key players in the tourism industry of an area aren't careful, it can be very easy to deplete that region of resources in order to meet the demand and growth of tourism. sustainable tourism development in Egypt -as a tourist destination ensure that construction, maintenance, infrastructure and the providing of services related to tourism are undertaken in ways that do not negatively affect local resources nor the community in which tourism thrives. 
Meets Both Profitability and Viability in Tourism Business: Characteristics of sustainable tourism must ensure that tourism markets served emphasize can be both profitable and viable for the long-term. Seeking only to gain as much profit as possible will require the tourism industry to move on, leaving the local economy and community in shambles.

Becomes Part of the Local Culture: One of the most important characteristics of sustainable tourism is that it does not take over the local culture and community.

The tourism industry should not detract from the special feel of a place and what makes it unique. A careful balance must be maintained in this endeavor to prevent loss of the original appeal to sustainable tourists.

Reinvests In Egypt- As A Tourist Destination: In order to maintain viability in a way that is friendly to the local community in Egypt that attract the sustainable tourists, it is absolutely essential that one of the characteristics of sustainable tourism be reinvestment in Egypt- as tourist destination. Money must be put back into the local schools, natural resources and infrastructure to meet the demands of international tourists that place on the destination.

Enhancing Safety And Security: Creating a hygiene unit to monitor food and beverage quality; using rapid response emergency systems; applying new system of classification for hotels and tourist resorts; introducing advanced security systems in hotels; developing a tourism awareness campaign for locals; enhancing Egypt image which direct broadcasts images from cameras installed in tourist areas to reassure visitors of the stability of key destinations including Hurghada ,Cairo, Luxor, Aswan, and Sharm El Sheikh.

Marketing And Promotion: High impact public relations and advertising campaigns, and enhanced E-marketing, particularly targeting high potential markets such as China, India and Scandinavian countries .

- Improving service quality: Education and vocational training and applying accreditation and certification systems.

-Enhancing sustainability: Establishing a green tourism unit, egyprt as a green destination and green star hotel ; friendly and social responsible management of hotels; enhancing environmental awareness; pursuing energy efficiency; encouraging the use of solar and renewable energy sources; reducing water consumption; and maintaining the biodiversity and reducing solid/liquid waste and carbon emissions.

-Making institutional changes: Tourism Development Authority and Ministry of Tourism as a one stop-shop for licenses and permits; launching an intranet system linking five and four star hotels with the Egyptian Hotels Association and Ministry; and gathering selected independent professionals to provide skills and experience. o Providing visas on arrival for many source market countries and provide support for new or enhanced transport routes.

\section{References}

Ajzen, I., and Fishbein, M. (1980). Understanding attitudes and predicting behavior. Englewood Cliffs, NJ: Prentice-Hall.

Andereck, K.L. (2009). Tourists' perceptions of environmentally responsible innovation at tourism businesses. Journal of Sustainable Tourism, 17(4), 489-499.

Bagozzi, R.P. and Warshaw, P.R. (1990). Trying to consume. Journal of Consumer Research, 17, 127-140.

Baker, M.A., Davis, E.A. and Weaver, P.A. (2014). Eco-friendly attitudes, barriers to participation, and differences in behavior at green hotels. Cornell Hosp Q, 55, 88-99. 
Balderjahn, I. (1988). Personality variables and environmental attitudes as predictors of ecologically responsible consumption patterns. Journal of Business Research, 17, 51-56.

Berger, I. and Corbin, R.M. (1992). Perceived Consumer Effectiveness and Faith in Others as Moderators of Environmentally Responsible Behaviors," Journal of Public Policy and Marketing, 11, 79-89.

Berger, I. (1997). The Demographics of Recycling and the Structure of Environmental Behavior. Environment and Behavior, 29(4):515-531.

Brechin, S.R. (1999). Objective Problems, Subjective Values, and Global Environmentalism: Evaluating the Postmaterialist Argument and Challenging a New Explanation. Social Science Quarterly, 80(4):793-811.

Bruvoll, A, Halvorsen, B.and Nyborg. K (2002). Households' Recycling Efforts. Resources Conservation and Recycling, 36(4):287-354.

Buhalis, D. (2003). eTourism: information technology for strategic tourism management. London: Financial Times/Prentice Hall.

Byrd, E.T. (2007). Stakeholders in sustainable tourism and their role: Applying stakeholder theory to sustainable development. Tourism Review, 62: 6-13.

Chien-Wen and Tsai, C. (2008). Impacts of Consumer Environmental Ethics on Consumer Behaviors in Green Hotels. Journal of Hospitality\&Leisure Marketing, 17, 284-313.

Choi, G.andParsa, H.G. (2008). A comparative study of consumers' green practice orientation in India and the United States: A study from the restaurant industry. Journal of Food Service Business Research, 11(3), 269-285.

Choi, G., Parsa, H.G., Sigala, M. and Putrevu. S. (2009). Consumers' environmental concerns and behaviors in the lodging industry: A comparison between Greece and the United States. Journal of Quality Assurance in Hospitality \& Tourism, 10(2): 93-112.

Corral-Verdugo, V. (2003). Situational and Personal Determinants of Waste Control Practices in Cross National Study. Society and Natural Resources, 20(10), 883-898.

De Groot, J. and Steg, L. (2006). Impact of transport pricing on quality of life, acceptability, and intentions to reduce car use: An exploratory study in five European countries. Journal of Transport Geography, 14 (6): 463-70.

De Young, R (1986). Some Psychological Aspects of Recycling: The Structure of Conservation Satisfactions. Environment and Behavior, 18, 435-449.

De Young, R. (1985). Encouraging Environmentally Appropriate Behavior: The Role of Intrinsic Motivation. Journal of Environmental Systems, 15(4):281-292.

Derksen, L. and Gartrell, J. (1993). The Social Context of Recycling. American Sociological Review, 58, 434-442.

Dunlap, R, andYork, R. (2008). The Globalization of Environmental Concern and the Limits of the post materialist values explanation: Evidence from four multinational surveys. The Sociological Quarterly, 49(3), 529-563.

Earth Charter Initiative. The Earth Charter. (2000). Available from http://www.earthcharterinaction.org/ content/pages/Read-the-Charter.html (accessed August, 2013).

Fairweather, J. R., Maslin, C., and Simmons, D. G. (2005). Environmental values and response to ecolabels among international visitors to New Zealand. Journal of Sustainable Tourism, 13(1), 82-98. 
Fishbein, M. and Ajzen, I. (1975). Belief, Attitude, Intention and Behavior, Reading, MA: Addison-Wesley. Fishbein-Ajzen Model, Journal of Hospitality Leisure Marketing, 5(4), 521.

Guerin, D., Crete, J. andMerecier, J. (2001). A Multilevel Analysis of the Determinants of Recycling Behavior in the European Countries. Social Science Research, 30(2), 195-218.

Hage, O., Soderholm, P. and Berglund, C. (2009). Norms and Economic Motivation in Household Recycling: Empirical Evidence from Sweden. Resources Conservation and Recycling, 53(3), 155-165.

Han, H., Hsu, L.J., Lee, J. and Sheu, C. (2010). Are lodging customers ready to go green? An examination of attitudes, demographics, and eco-friendly intentions. International Journal of Hospitality Management, 30, 345-355.

Hansla, A., Gamble, A., Juliusson, A. and Ga"rling, T. (2008). The relationships between awareness of consequences, environmental concern, and value orientations. Journal of Environmental Psychology, 28(1), 1-9.

Hopper, J. and Nielson, J.M. (1991). Recycling as Altruistic Behavior: Normative and Behavioral Strategies to Expand Participation in a Community Recycling Program. Environment and Behavior, 23, 195-220.

Irene M. Herrem (2002). Developing awareness of the sustainability concept. The Journal of Environmental Education, Vol. 34, No. 1, pp. 16-20

Jackson, A.L., Olson, J.E. Granzin, K.L. \& Burns, A.C. (1992). An Investigation of the Determinants of Recycling Consumer Behavior. In: McAlister, L. Rothschild, M. (eds). Advances in Consumer Research. Salt Lake City, UT: Association for Consumer Research, 481-487.

Kahle, L.R. (1983). Social values and social change: Adaptation to life in America. New York: Praeger.

Kinnear, T.C., Taylor, J.R. \& Ahmed, S.A. (1974). Ecologically Concerned Consumers: Who Are They?. Journal of Marketing, 38, 20-24.

Leiserowitz, A.A., Kates, R.W. \& Parris, T.M. (2006). Sustainability values, attitudes, and behaviors: A review of multinational and global trends. Annual Review of Environment and Resources, 31 (1): 413-44.

Lee, ChwenSheu (2010). "Are lodging customers ready to go green? An examination of attitudes, demographics, and eco-friendly intentions", International Journal of Hospitality Management, Vol. 7

Mair, J. and Bergin-Seers, S. (2010). The effect of interventions on the environmental behavior of Australian motel guests. Tourism and Hospitality Research, 10(4), 255-268.

Marqart-Pyatt, S.T. (2007). Concern for the Environment among General Publics: A Cross National Study. Society and Natural Resources, 20(10): 883-898.

McCarty, J.A. and Shrum, L.J. (1993). A Structural Equation Analysis of the Relationships of Personal Values, Attitudes and Beliefs about Recycling, and the Recycling of Solid Waste. Advances in Consumer Research, 20, 641-646.

Mehmetoglu, M., Hines, K., Graumann, C. and Greibrokk. J. (2010). The relationship between personal values and tourism behaviour: A segmentation approach. Journal of Vacation Marketing, 16(1), 17-27.

Milfont, T.L., Duckitt, J and Cameron, L.D. (2006). A Cross-Cultural Study of Environmental Motive Concerns and Their Implications for Pro environmental Behavior. Environment and Behavior, 38(6):745-767. 
Mitchell, A. (1983). The nine American life styles. New York: Warner. Mitchell.

Nepal, S.K. (2007). Ecotourists' importance and satisfaction ratings of accommodationrelated amenities. Anatolia, 18, 255-276.

New York: United Nations.

Nielson, J.M. and Ellington, B.L. (1983). Social processes and resource conservation: A case study in low technology recycling. In: Nickolaus R.F. \& Geller, ES (eds). Environmental psychology: Directions and perspectives. New York: Praeger; pp. 288-311.

Noor, N.A.M. \& Kumar, D. (2014). ECO friendly 'activities' VS ECO friendly 'attitude': Travelers intention to choose green hotels in Malaysia. World Applied Sciences Journal, 30, 506-513.

Nordlund, A.M. and Garvill, J. (2002). Value structures behind pro environmental behavior. Environment and Behavior, 34(6), 740-56.

Olli, E., Grendstad, G.and Wollebaek, D. (2001). Correlates of Environmental Behaviors Bringing Back Social Context. 33(2).

Parasuraman, A., Zeithaml, V.A. and Berry, L.L (1985). A Conceptual Model of Service Quality and Its. Implications for Future Research. Journal of Marketing, 49(4): 41-50.

Raskin, P., Banuri, T., Gallopin, G., Gutman, P., Hammond, A.L., Kates, R. and Swart, R. (2002). Great transition: The promise and lure of the times ahead. Boston: Stockholm Environment Institute ready to go green? An examination of attitudes, demographics, and eco-friendly Recycling, 39(3), 265-281.

Rohan, M.J. (2000). A rose by any name? The values construct. Personality and Social Psychology Review, 4(3):255-277.

Samdahl, D.M. and Robertson, R. (1989). Social Determinants of Environmental Concern: Specification and Test of the Model. Environment and Behavior, 21, 57-81.

Schultz, P.W.and Zelezny, L. (1999). Values as predictors of environmental attitudes: Evidence for consistency across 14 countries. Journal of Environmental Psychology, 19(3), 255-265.

Schultz, P.W. (2001). The structure of environmental concern: Concern for self, other people, and the biosphere. Journal of Environmental Psychology, 21(4), 327-339.

Schwartz, S. H. (2006). A theory of cultural value orientations: Explication and applications. Comparative Sociology, 5(2-3), 137-182.

Schwartz, S.H. andRubel-Lifschitz, T. (2009). Crossnational variation in the size of sex differences in values:Effects of gender equality. Journal of Personality and Social Psychology, 97 (1): 171-185.

Schwartz, S.H. (1992). Universals in the content and structure of values: Theoretical advances and empirical tests in 20 countries. Advances in Experimental Social Psychology, 25, 1-65.

Schwartz, S.H., Lilach Sagiv, and Boehnke, K. (2000). Worries and values. Journal of Personality, 68(2), 309-346.

Shepherd, D.A., Kuskova, V. and Patzelt, H. (2009). Measuring the values that underline sustainable development: The development of a valid scale. Journal of Economic Psychology, 30(2), 246-256.

Sidique, S. F., Lupi, F., and Joshi, S. V. (2010). The effects of behavior and attitudes on drop-off recycling activities. Resources, Conservation and Recycling, 54(3), 163-170.

Spash, C. L. (2002). Informing and forming preferences in environmental valuation: Coral reef biodiversity. Journal of Economic Psychology, 23(5), 665-689.

Statistics Canada. (2010). Recycling by Canadian Households, 2007, Cat.No. 16001-M No. 13. 
Stern, P. C. \& Dietz, T. (1994). The value basis of environmental concern. Journal of Social Issues, 50(3), 65-84.

Stern, P.C. (2000). Psychology and the science of human-environment interactions. American Psychologist, 55(5), 523-530.

Stern, P.C., Dietz, T. and Guagnano, G.A. (1998). Social structural and social psychological bases of environmental concern. Environment and Behavior, 30(4), 450-471.

Stern, P.C., and Guagnano, G.A. (1998). A brief inventory of values. Educational and Psychological Measurement, 58, 984-1001.

Stern, P.C., Kalof, L., Dietz, T. and Guagnano, G.A. (1995). Values, beliefs, and proenvironmental action: Attitude formation toward emergent attitude objects1. Journal of Applied Social Psychology, 25(18), 1611-1636.

United Nations. (2000). The United Nations Millennium Declaration.

Van Lange, P. A. M., Otten, W., De Bruin, E. M. N., \& Joireman, J. A. (1997). Development of Prosocial, Individualistic, and Competitive Orientations: Theory and Preliminary Evidence. Journal Personality and Social Psychology,73(4), 733-746.

Van Vugt, M., Meertens, R.M. and Van Lange, P.A.M. (1995). Car versus public transportation? The role of social value orientations in a real-life social dilemma. Journal of Applied Social Psychology, 25(3), 258-278.

Vaske, J.J. and Donnelly, M.P. (1992). A value-attitude behavior model predicting wild land preservation voting intentions. Society \& Natural Resources, 12(6), 523-537.

Vining, J. and Ebreo, A. (1990). What Makes a Recycler? A Comparison of Recyclers and No recyclers. Environment and Behavior, 22, 55-73.

Vining, J. and Ebreo, A. (1992). Predicting Recycling Behavior from Global and Specific

Environmental Attitudes and Changes in Recycling Opportunities. Journal of Applied Social Psychology, 22(20), 1580-1607.

Woodall, T., (2003). Conceptualizing 'value for the customer': an attribution, structural and dispositional analysis. Academy of Marketing Science Review, 12(12), 1-37.

World Summit on Sustainable Development. 2002. The Johannesburg Declaration on sustainable development.

http:/www.unescap.org/esd/environment/rio20/ (accessed January 23, 2017).

World Bank. Egypt Data Profile, 2016. http://www.worldbank.org. World Bank. Project Information Document. Egypt Umbrella Program for Health System Development. Project Information Document. Report no. AB2077. http://www.worldbank.org / (accessed Fep.2017)

Investment Climate Statement, Egypt, US Department of State, Jan, 2015, http://www.state.gov/e/eb/rls/othr/ ics/2015/241546.htm. (Accessed Dec.2016). 